\title{
Life cycle assessment of oil palm empty fruit bunch delignification using natural malic acid-based low-transition-temperature mixtures: a gate-to-gate case study
}

\author{
Chung Loong Yiin ${ }^{1} \cdot$ Suzana Yusup ${ }^{1} \cdot$ Armando T. Quitain ${ }^{2,3} \cdot$ Yoshimitsu Uemura $^{1} \cdot$ Mitsuru Sasaki $^{4} \cdot$ Tetsuya Kida $^{2}$
}

Received: 2 February 2018 / Accepted: 25 July 2018 / Published online: 31 July 2018

(c) Springer-Verlag GmbH Germany, part of Springer Nature 2018

\begin{abstract}
In future biorefineries, the development of cheap and environmentally friendly solvents for biomass pretreatment is highly desirable. In this sense, low-transition-temperature mixtures (LTTMs) have high potential to serve as green solvents for replacing conventional pretreatment technologies. In this study, a life cycle assessment of LTTMs pretreatment was conducted to determine the environmental impacts caused by biomass delignification. A gate-to-gate analysis which started with harvested oil palm empty fruit bunch and ended with lignin was selected. The environmental impacts such as acidification potential, global warming potential, eutrophication potential, photochemical ozone creation potential, human toxicity potential and volatile organic compounds emission were evaluated. The comparable environmental balances of commercial L-malic acid and cactus malic acid-based LTTMs pretreatment processes verified the suitability of the process with natural malic acid as the source of proton donor. This study concludes that biomass delignification using natural cactus malic acidbased LTTMs had promising features such as high delignification efficiency and environmentally friendly compared to commercial L-malic acid-based LTTMs. Based on environmental point of view, the overall process of biomass delignification using sucrose-based LTTMs had lower $\mathrm{CO}_{2}$ emissions compared to the monosodium glutamate- and choline chloride-based LTTMs. These findings are important for verifying the greenness and sustainability of LTTMs to be applied at industrial scale.
\end{abstract}

Keywords Biomass $\cdot$ Delignification $\cdot$ Cactus $\cdot$ Malic acid $\cdot$ Low-transition-temperature mixture $\cdot$ Life cycle assessment

\section{Introduction}

The high consumption of fossil fuels- and petroleum-based materials which coupled with greenhouse gases (GHGs) emission has upraised the awareness of researchers to search for renewable resources as sustainable energy systems (Spiridon et al. 2016). Different strategies have been

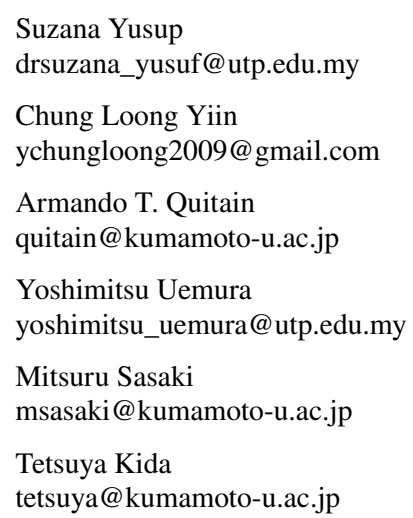

reinforced for avoiding the production and use of petrochemical-based alternatives (Gullón et al. 2018). In this context, lignocellulosic biomass is considered as an untapped and renewable source of feedstocks for the production of bioproducts and biomaterials (Chen et al. 2015). There are three main components in lignocellulosic biomass, namely cellulose, hemicelluloses and lignin which assembled in a

1 Biomass Processing Cluster, Centre for Biofuel and Biochemical Research, Chemical Engineering Department, Institute of Self-Sustainable Building, Universiti Teknologi PETRONAS, 32610 Seri Iskandar, Perak, Malaysia

2 Department of Applied Chemistry and Biochemistry, Faculty of Advanced Science and Technology, Kumamoto University, 2-39-1 Kurokami, Chuo-ku, Kumamoto 860-8555, Japan

3 College of Cross-Cultural and Multidisciplinary Studies, Kumamoto University, 2-40-1 Kurokami, Chuo-ku, Kumamoto 860-8555, Japan

4 Institute of Pulsed Power Science, Kumamoto University, 2-39-1 Kurokami, Chuo-ku, Kumamoto 860-8555, Japan 